\title{
Volcano Popocatepetl, Mexico: ULF geomagnetic anomalies observed at Tlamacas station during March-July, 2005
}

\author{
A. Kotsarenko ${ }^{1}$, V. Grimalsky ${ }^{2}$, R. Pérez Enríquez ${ }^{1}$, C. Valdez-González ${ }^{3}$, S. Koshevaya ${ }^{2}$, J. A. López Cruz-Abeyro ${ }^{1}$, \\ and V. Yutsis ${ }^{4}$ \\ ${ }^{1}$ Centro de Geociencias en Juriquilla, UNAM, Apdo Postal 1-742, Centro Querétaro, Querétaro, México, C.P. 76001, México \\ ${ }^{2}$ UAEM, Cuernavaca, Morelos, México \\ ${ }^{3}$ Instituto de Geofísica, UNAM, México D.F., México \\ ${ }^{4}$ UANL, Facultad de Ciencias de la Tierra, Linares, Nuevo Len, México
}

Received: 17 July 2006 - Revised: 5 December 2006 - Accepted: 6 December 2006 - Published: 24 January 2007

\begin{abstract}
In this paper the first results of ULF (Ultra Low Frequency) geomagnetic anomalies observed at Tlamacas station (Long. 261.37, Lat. 19.07) located at $4 \mathrm{~km}$ near the volcano Popocatepetl (active volcano, Long. 261.37, Lat. 19.02) for the period March-July, 2005 and their analysis are presented. The geomagnetic data were collected with a 3-axial fluxgate magnetometer designed at UCLA (University of California, Los Angeles, $1 \mathrm{~Hz}$ sampling rate frequency, GPS). Our analysis reveals some anomalies which are suspected to be generated by local volcanic origin: the EM background in the vicinity of the volcano is significantly noisier than in other reference stations; the sporadic strong noise-like geomagnetic activity observed in the $\mathrm{H}$ component; locally generated geomagnetic pulsations (without preferred polarization) are detected only at Tlamacas station.
\end{abstract}

\section{Introduction}

The object of our interest, the Popocatepetl volcano (nick named El Popo, Fig. 1a), is located in Central Mexico (Long. 261.37, Lat. 19.07, elevation $5465 \mathrm{~m}$ ). It is one of several active volcanoes that form the Trans-Volcanic Belt of Mexico (also know as Neo-Volcanic Axes) and its existence is related to the geodynamics of the North American and Coco plates. El Popo is a major geological hazard in Mexico: if a sudden eruption would take place (Fig. 1b), it could result in one of the most dramatic natural disasters in the contemporaneous history of Mexico due to the fact that El Popo is situated near one of the world's most populated areas: Mexico City (about $70 \mathrm{~km}$ southeast) and the nearby populations of Puebla (about $45 \mathrm{~km}$ west) and Cuernavaca

Correspondence to: A. Kotsarenko

(kotsarenko@geociencias.unam.mx) (about $60 \mathrm{~km}$ northeast) among others. More than 30 million people live within view of the volcano and hundreds of thousands of people would be endangered by hazards associated with a large explosive eruption of the volcano (Macías Vázquez et al., 1995). A major eruption would have serious consequences for people living in communities on the flanks of the volcano, and ash from such an eruption could also endanger aircraft using Mexico City international airport.

About 30 eruptions have been reported in historical time (although documentation is poor); the latest significant activity took place in 1920-1922. At present, El Popo is a intermittent source of ash, periodically polluting nearby metropolitan areas (Juárez et al., 2005). Due to all this, the Popocatepetl volcano is the object of constant seismic and volcanic monitoring by CENAPRED (National Mexican Center for Prevention of Disasters) and therefore our own interest to establishing geomagnetic stations for continuous monitoring.

Different long-term ULF (Ultra Low Frequency, 1$100 \mathrm{~Hz}$ ) Electro-Magnetic band observations from all over the world (see the comprehensive monographs by Hayakawa, 1994, 1999, and Hayakawa and Molchanov, 2002) point these as very promising for monitoring EM emission generated in the period preceding strong seismic events. The number of volcano-related EM studies is still small but some of them deserve mentioning (Currenti et al., 2005; Enomoto, et al., 2006; Fujinawa et al., 2006; Kotsarenko et al., 2005b) as they provide the possibility of generation of similar signals associated with volcanic activity. In terms of this, the main aim of our study was to analyze reliable geomagnetic data observed at the Tlamacas station, Popocatepetl, obtained during the period of March-July, 2005, to look for anomalies which could be related to geodynamical processes produced by volcano Popocatepetl.

Published by Copernicus GmbH on behalf of the European Geosciences Union. 

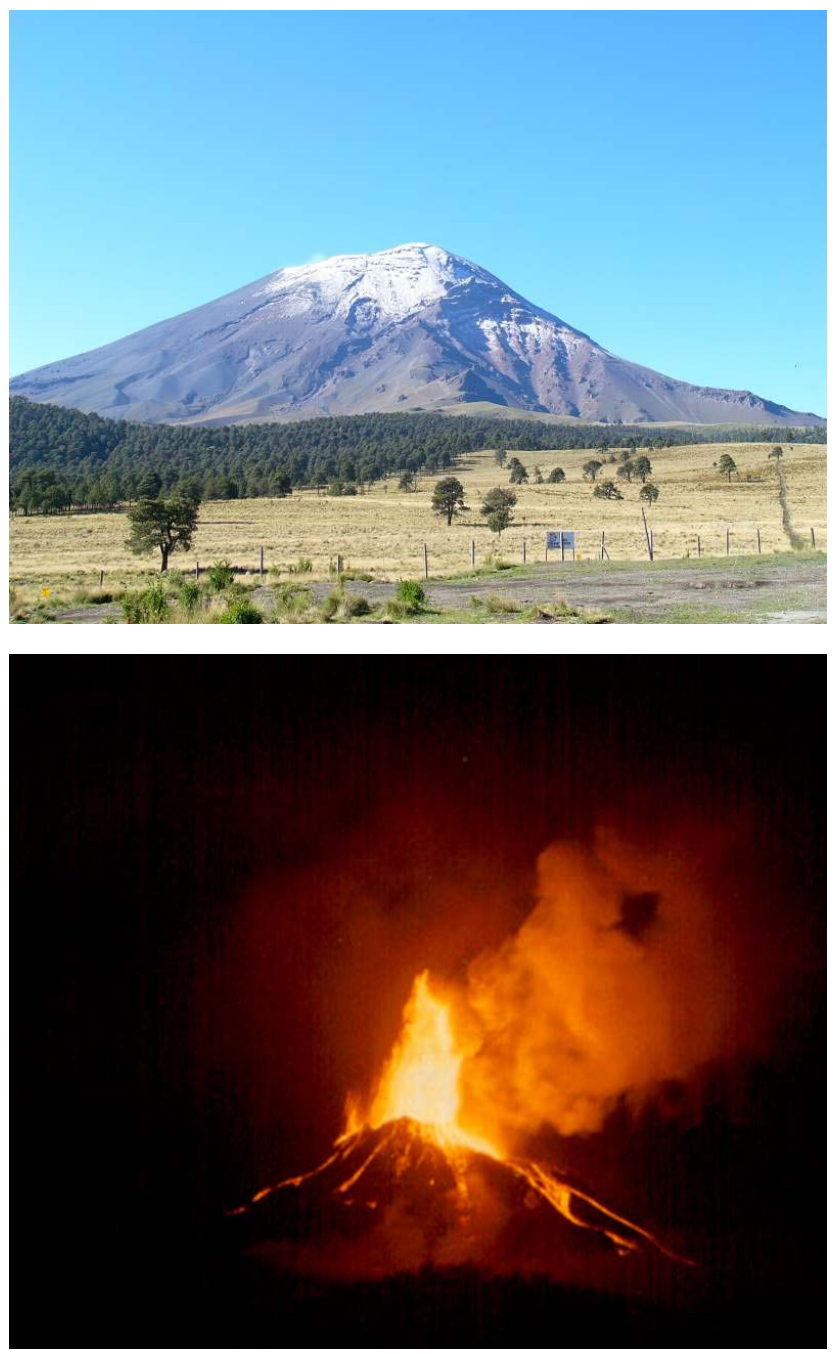

Fig. 1. Quiet volcano, January 2005 (top, a). Lava eruption, December 2000 (bottom, b).

\section{Experiment and results}

The geomagnetic monitoring of the volcano Popocatepetl was established on March 8, 2002 as a complimentary part of the Tlamacas seismic station (CENAPRED, Long. 261.37, Lat. 19.02), which is located within $4 \mathrm{~km}$ of the volcano crater (Fig. 2a, b). The first data collected by a Torsion type 3-axial magnetometer (GPS-synchronization, $50 \mathrm{~Hz}$ sample frequency, designed at St-Petersburg Division of IZMIRAN) appeared to be contaminated by an intensive periodical multi-band noise coming from near-buried seismograph cables, and the precision of the instrument went down. The data collection was renewed in 2003 with a 3-coordinate fluxgate magnetometer (GPS, $1 \mathrm{~Hz}$, designed at UCLA). The results obtained for the 2003-2004 (Kotsarenko et al., 2005a) could be considered unreliable, since the observation spots covered short time intervals due to the occurrence of numerous power cuts. The installation of a powerful USP system in
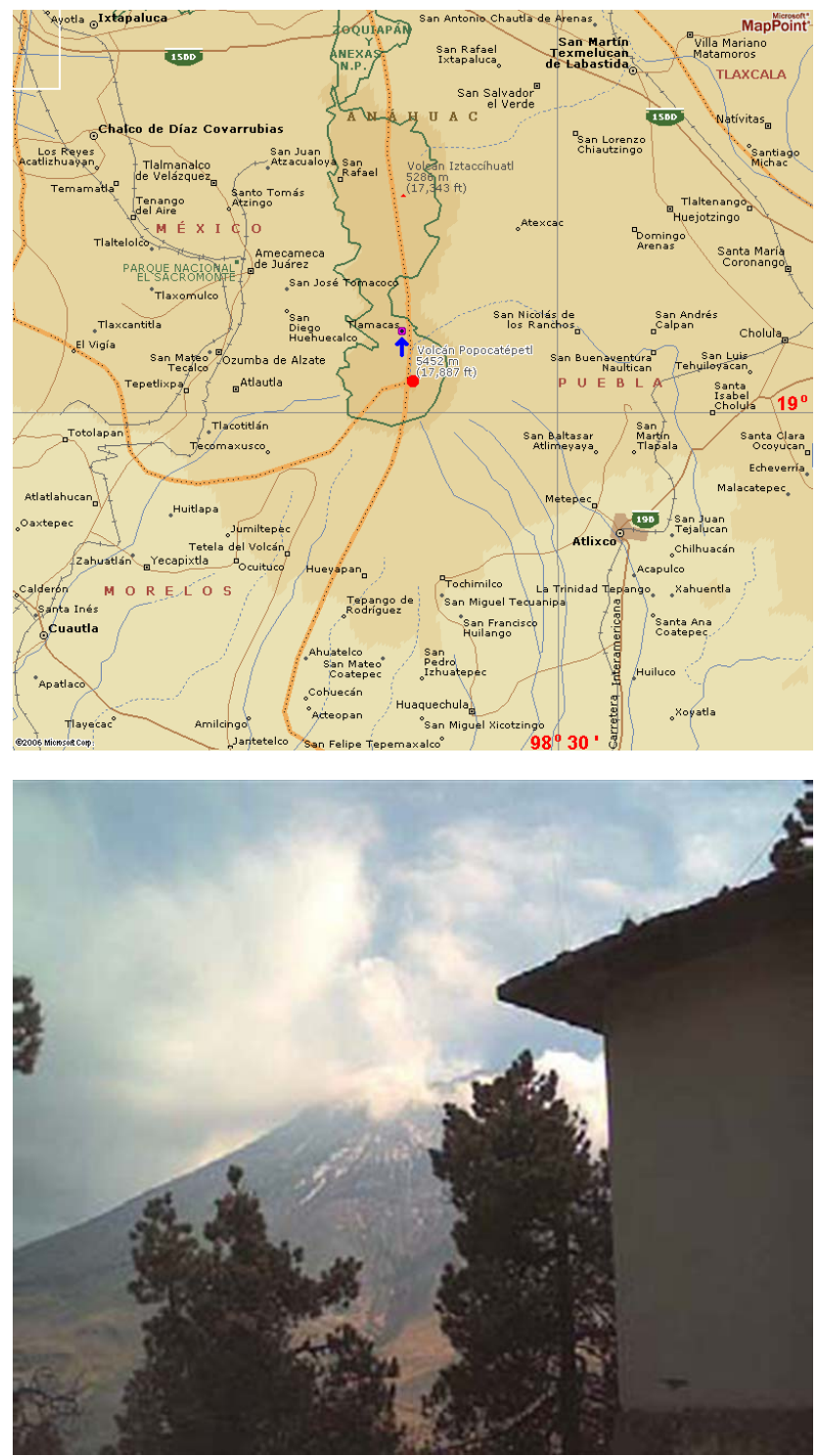

Fig. 2. Map of the volcano Popocatepetl (marked by the red circle) and Tlamacas station (blue arrow) - (top, a). A view for the light volcano eruption (water and gases) from the Tlamacas station - (bottom, b).

2005 permitted us to collect a five-month interval of constant monitoring data (March-July, 2005), which are analyzed in this paper.

Our study includes the analysis of dynamic spectra as part of a traditional analysis for the continuous component of the magnetic field and the analysis of geomagnetic micropulsations for the pulse component. Temporal intervals with high geomagnetic activity (estimated with the aid of the equatorial $D_{s t}$ index) are normally discarded from the analysis. In order to distinguish the local character of the observed phenomena from the global ones, we compared our results with those calculated for a reference station (the closest 


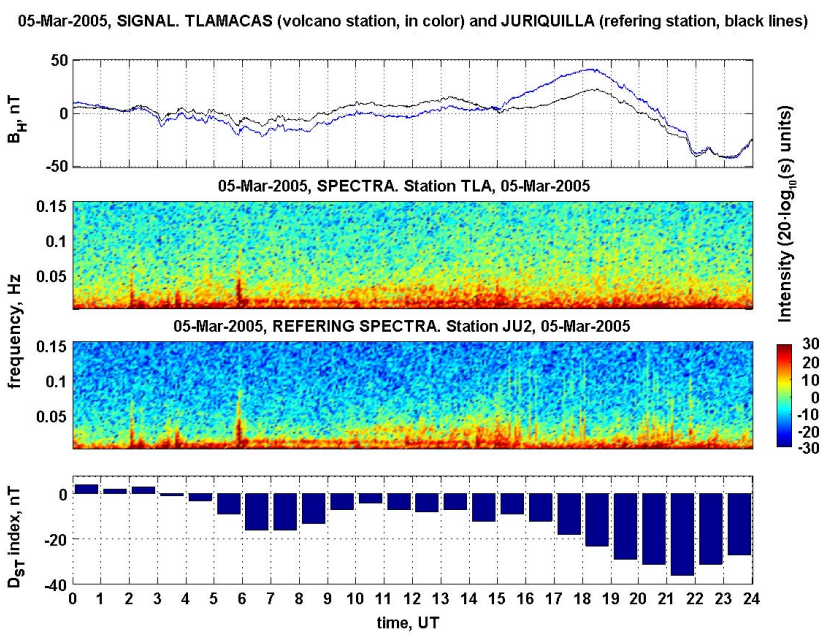

Fig. 3. The spectral intensity of the noise background is higher in the Tlamacas, 2nd panel: domination of more intensive orange colors in contrary to the weaker green and blue seen at the 3rd panel, Juriquilla, the reference station. Top panel: H-component signals, Tlamacas (blue line) and Juriquilla (black). 2nd and 3rd panel: Tlamacas and Reference spectrogram accordingly. Bottom panel: $D_{s t}$ index of geomagnetic activity.

Mexican station Juriquilla, Long. 259.6, Lat. 20.6) integrated to the Mid-Continent Magneto-seismic Chain network and equipped with the same instrument (McMAC, see Chi et al., 2005).

The analysis of the obtained results shows the following tendencies:

1. The general EM background in the vicinity of the volcano is significantly noisier than in Juriquilla (Fig. 3). The observed feature has a mostly permanent character.

2. Srong noise-like geomagnetic activity in the $\mathrm{H}$ component of the magnetic field with intensity up to tens of gammas (nanoteslas) and duration from several hours up to 1-2 days was detected 13 times during the time of observations (Fig. 4). The physical cause of the mentioned phenomena is still unclear. For instance: the strongest event shows a change of base value of about $100 \gamma$ while a noise amplitude of about $50 \gamma$ (presented in Fig. 4), was observed in the geomagnetically quiet period, 2 days after the volcano-tectonic earthquake (magnitude 2.7 , depth $4.0 \mathrm{~km}$ ) and under a moderate number of volcanic eruptions (15 eruptions during this day). More detailed discussion of the possible cause of the phenomena is presented in the next chapter.

3. Some geomagnetic pulsations are detected at Tlamacas station that were not observed in the reference station data. The phenomena presented in Fig. 5, occurred during the intensive fumarolic eruption (the eruption began at 11:21 (UT), the cloud elevated up to $1500 \mathrm{~m}$, moving

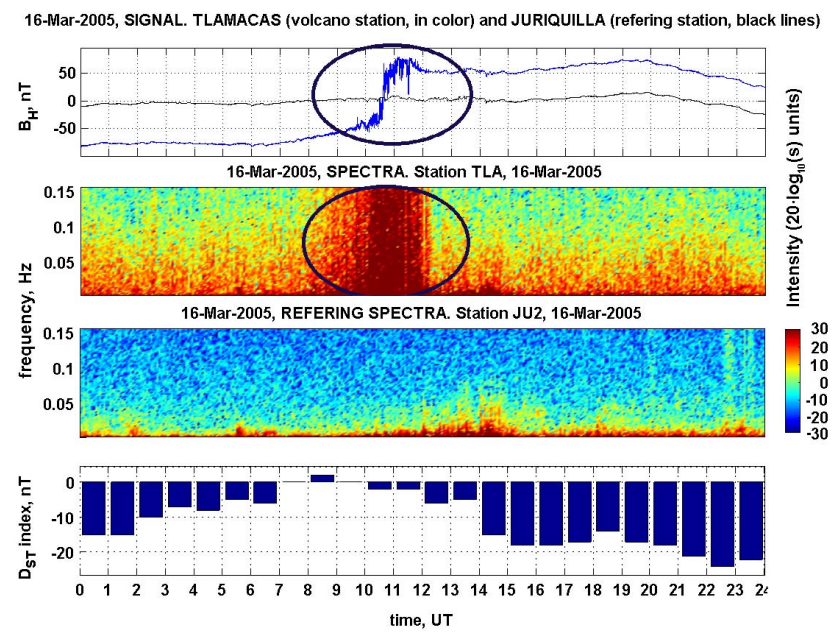

Fig. 4. The intensive perturbation observed in the signal at Tlamacas station (blue line) compared with a reference (Juriquilla) signal (back line, top panel) and its spectra (2nd panel). Bottom panel: $D_{s t}$ index of geomagnetic activity. The Perturbation and its spectra are marked by ellipses.

in the North-East direction). The observed pulsations normally do not reveal any dominant direction (arbitrary polarization).

\section{Discussion}

As the observed phenomena were free from EM industrial noise place, and taking into account the relatively short time of our observation, we present here some possible models to explain the mentioned anomalies:

1. As the magma itself possess good conductive properties, convective circular motion in the magmatic reservoir may create a perturbed magnetic field due to a selfinduction effect.

2. The thermal heating may induce re-magnetization processes in the rock medium.

3. Different mechanisms of micro-fracturing (already developed) may be enhanced by conductive currents in the lava.

4. The effect of the magneto-striction simulated by stressed rock movement may also be a possible source of the generated emission (in analogy to the electrostriction).

Among the observed anomalies one (the highly perturbed H-component, Fig. 4) is a subject of a special interest and should be discussed separately. As we did not detect any perturbation either in D- or vertical (Z-) components of the geomagnetic field, such polarization assumes certain anisotropy 


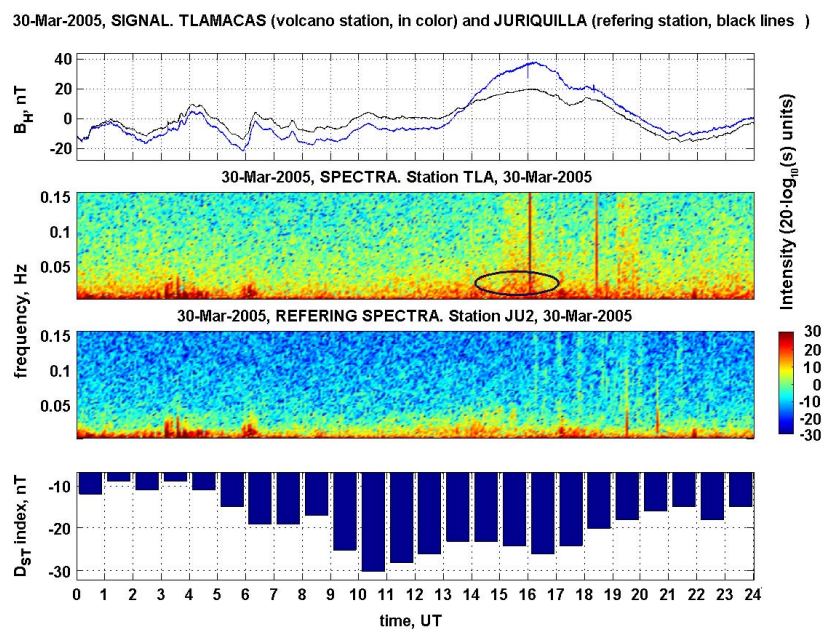

Fig. 5. The table of symbols is the same as in Figs. 3-4. The example of locally generated geomagnetic micro-pulsation during the eruption (see Fig. 6) is marked by an ellipse.

in the mechanism of its generation. In other words, the source responsible for it should have a specific geometry. The two mechanisms proposed before (re-magnetization and micro-fracturing) cannot produce the necessary effect because of their pure isotropic character. The last two mechanisms can theoretically generate a perturbation in the mentioned $\mathrm{H}$-component under particular circumstances. For instance: the magmatic reservoir is flat in the plane perpendicular to the N-S direction, so the circular magmatic motion takes place almost in the mentioned plane, producing the necessary contribution to the geomagnetic field in the $\mathrm{H}$ component only (as the volcano crater is located almost in the S-N line, see Fig. 2a).

However, all the observed phenomena remain the object of future serious study and revision. We plan to establish more stations in the vicinity of the volcano to be able to detect the direction to the source (a complete set includes 4 stations) of the anomalies. Furthermore, complementary geophysical studies (such as gravimetric and magneto-telluric) in the area of the volcano can be very useful in revealing the possible anomalies in the configuration of the underground magmatic reservoir or specific rock structure for the explanation of the mentioned polarization (H-component) of highly-perturbed geomagnetic field measurements.

\section{Conclusions}

In the present paper we described the geomagnetic anomalies observed in the vicinity of the volcano Popocatepetl, such as the EM noise background, sporadic and strong burst-like activity, and locally generated geomagnetic micro-pulsations, which could be related to the activity of the volcano and therefore can serve as another perspective tool to study

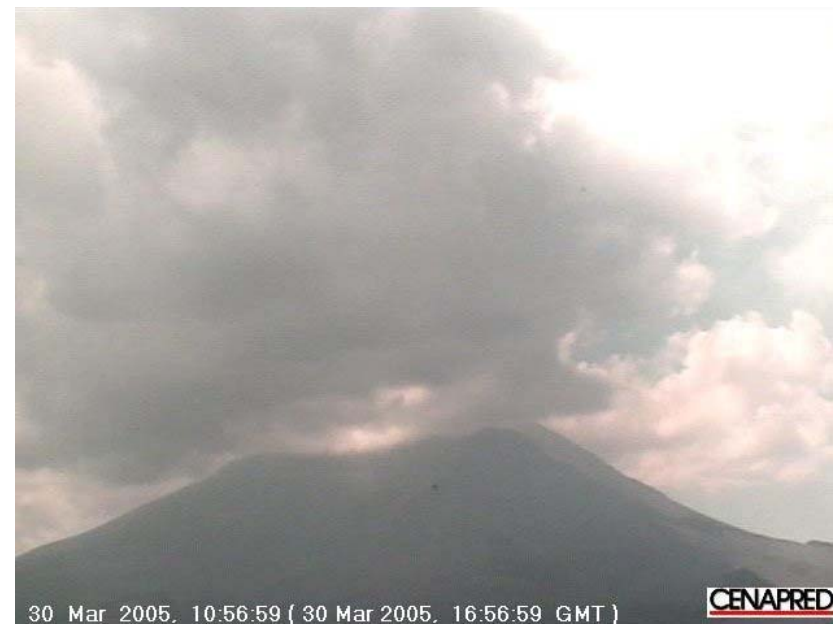

Fig. 6. Moderate eruption (fumarola), 30 March 2005. Mexico National Center of Prevention of Disasters (CENAPRED) photo.

the volcanic geodynamical processes, besides the traditional ones. However, future experimental observations are necessary to be able to choose between the physical mechanisms that were provisionally proposed. These should be then extended to comply with more reliable models obtained from simulations using real geophysical parameters.

Acknowledgements. This work was supported by Mexican government foundation CONACyT (project CONACyT 47662) and partially supported by internal UNAM foundation DGAPA (project PAPIIT IN117106), respectively. We also thank P. Chi for providing us with the referring McMAC data. The authors are grateful to N. A. Smirnova and another anonymous referee for suggestions and remarks that have given us the possibility to improve the text of the manuscript. Special thanks to the Regional Coordinator of the Institute of Civil Defense Sr. C. Marcos Galicia López for his voluntary help and concern about Tlamacas station.

Edited by: P. F. Biagi

Reviewed by: N. A. Smirnova and another referee

\section{References}

Chi, P. J., Engebretson, M. J., Moldwin, M. B., Russell, C. T., Mann, I. R., Samson, J. C., López Cruz-Abeyro, J. A., Yumoto, K., and Lee, D.-H.: Mid-continent Magnetoseismic Chain (McMAC): A Meridional Magnetometer Chain for Magnetospheric Sounding, Proceedings of the Enviroment Modeling Workshop, Snowmass, Colorado, USA, 2005.

Currenti, G., Del Negro, C., Lapenna, V., and Telesca, L.: Multifractality in local geomagnetic field at Etna volcano, Sicily (southern Italy), Nat. Hazards Earth Syst. Sci., 5, 555-559, 2005, http://www.nat-hazards-earth-syst-sci.net/5/555/2005/.

Enomoto, Y., Hashimoto, H., Shirai, N., Murakami, Y., Mogi, T., Takada, M., and Kasahara, M.: Anomalous geoelectric signals possibly related to the $2000 \mathrm{Mt}$. Usu eruption and 2003 TokachiOki earthquakes, Phys. Chem. Earth, 31, 319-324, 2006. 
Fujinawa, Y., Matsumoto, T., Iitaka, H., Takahashi, K., Nakano, H., Doi, T., Saito, T., Kasai, N., and Sato, S.: Earliest detection of magma movements by measuring transient streaming potential, Phys. Chem. Earth, 31, 223-233, 2006.

Hayakawa, M. and Fujinawa, Y. (Eds.): Electromagnetic Phenomena Related to Earthquake Prediction, Terra Sci. Pub. Co., Tokyo, Japan, 1994.

Hayakawa, M. (Ed.): Atmospheric and Ionospheric Electromagnetic Phenomena Associated with Earthquakes, TERRAPUB, Tokyo Japan, 1999.

Hayakawa, M. and Molchanov, O. A. (Eds.): Seismo Electromagnetics: Lithosphere-Atmosphere-Ionosphere Coupling, TERRAPUB, Tokyo, Japan, 2002.

Juárez, A., Gay, C., and Flores, Y.: Impact of the Popocatepetl's volcanic activity on the air quality of puebla City, Mexico, Atmósfera, 57-69, 2005.
Kotsarenko, A., Valdez-Gonzalez, C., López Cruz-Abeyro, J. A., Pérez Enríquez, R., Koshevaya, S., and Grimalsky, V.: Seismogenic ULF EM emissions of volcano origin, observed at Tlamacas seismo-geomagnetic station, volvano Popocatepetl, Mexico, 2001-2004, International Workshop on Seismo Electromagnetics IWSE, Programme and Extended Abstracts, 217-218, 2005a.

Kotsarenko, A., Molchanov, O., Hayakawa, M., Koshevaya, S., Grimalsky, V., Pérez Enríquez, R., and López Cruz-Abeyro, J. A.: Investigation of ULF magnetic anomaly during Izu earthquake swarm and Miyakejima volcano eruption at summer 2000, Japan, Nat. Hazards Earth Syst. Sci., 5, 63-69, 2005b.

Macías Vázquez, J. L., Carrasco Núñez, G., Delgado Granados, H., Martín Del Pozzo, A. L., Siebe Grabach, C., Hoblitt, R. P., Sheridan, M. F., and Tilling, R. I.: Mapa de peligros del volcán Popocatepetl, Instituto de Geofísica, UNAM, Mexico, http://tornado.cenapred.unam.mx/es/Instrumentacion/ InstVolcanica/MVolcan/ImagenesMVolcan/mapaPeligrosA.jpg, 1995. 